\title{
Small vessel coronary artery disease: How small can we go with myocardial revascularization?
}

\author{
Maciej T. Wybraniec ${ }^{1,2}$, Paweł Bańka ${ }^{1,2}$, Tomasz Bochenek ${ }^{1,2}$, \\ Tomasz Roleder ${ }^{3}$, Katarzyna Mizia-Stec ${ }^{1,2}$ \\ ${ }^{1}$ First Department of Cardiology, School of Medicine in Katowice, \\ Medical University of Silesia, Katowice, Poland \\ ${ }^{2}$ Upper Silesia Medical Center, Katowice, Poland \\ ${ }^{3}$ Regional Specialist Hospital, Research and Development Center, Wroclaw, Poland
}

\begin{abstract}
The issue of small coronary artery atherosclerosis represents an intriguing aspect of coronary artery disease, which is related with higher rates of peri- and post-procedural complications and impaired long-term outcome. This problem is further complicated by the unclear definition of small coronary vessel. Recent randomized controlled trials have provided new data on possible novel interventional treatment of small coronary vessels with drug-coated balloons instead of traditional new-generation drug-eluting stent implantation. Also, the conservative management represents a therapeutic option in light of the results of the recent ISCHEMIA trial. The current article provides an overview of the most appropriate definition, interventional management, and prognosis of small coronary artery atherosclerosis. (Cardiol J 2021; 28, 5: 767-778)
\end{abstract}

Key words: small coronary artery disease, small coronary vessel, small vessel disease, drug-coated balloons, drug-eluting stents

\section{Introduction}

The first successful percutaneous coronary intervention (PCI) was performed in 1977. Since this time interventional cardiology has made huge progress owing to rapid improvement of technology. However, treatment of stenoses in small coronary arteries remains an uncharted clinical territory in terms of decision-making and optimal technique of intervention. Depending on the applied definition, the prevalence of small vessel disease (SVD) reaches roughly $1 / 3$ of patients with symptomatic coronary artery disease (CAD) [1, 2], especially patients with chronic kidney disease (CKD) [3], diabetes mellitus [4], and active smokers [5-7].

The clinical significance of small vessel atherosclerosis is related to its frequently diffuse nature $[8,9]$. Although some patients may present with isolated one-vessel significant stenosis in a small coronary artery (Fig. 1), a considerable group of patients have diffuse atherosclerosis not amenable to endovascular and surgical revascularization (Fig. 2). In this clinical scenario, only optimal medical therapy represents a therapeutic option, and SVD should be regarded as an end-stage phase of CAD [10]. Also, it is important to distinguish SVD from coronary microvascular spasm, which represents a different clinical entity not amenable to percutaneous intervention but tailored for a pharmacological approach [11].

This article, however, primarily discusses clinical scenarios, in which revascularization is a therapeutic option, alongside the best medical therapy (Fig. 1). In this case, one should take into consideration the possible clinical benefits and complications of PCI performed in such clinical circumstance. On the one hand, even a small ischemic territory can cause debilitating angina,

Address for correspondence: Maciej T. Wybraniec, MD, PhD, First Department of Cardiology, School of Medicine in Katowice, Medical University of Silesia, ul. Ziołowa 47, 40-635 Katowice, Poland, tel: +48 3235988 90, fax: +48 32 2523032, e-mail: maciejwybraniec@gmail.com

Received: 8.04.2020 Accepted: 21.07.2020 Early publicaion date: 21.09.2020

This article is available in open access under Creative Common Attribution-Non-Commercial-No Derivatives 4.0 International (CC BY-NC-ND 4.0) license, allowing to download articles and share them with others as long as they credit the authors and the publisher, but without permission to change them in any way or use them commercially. 


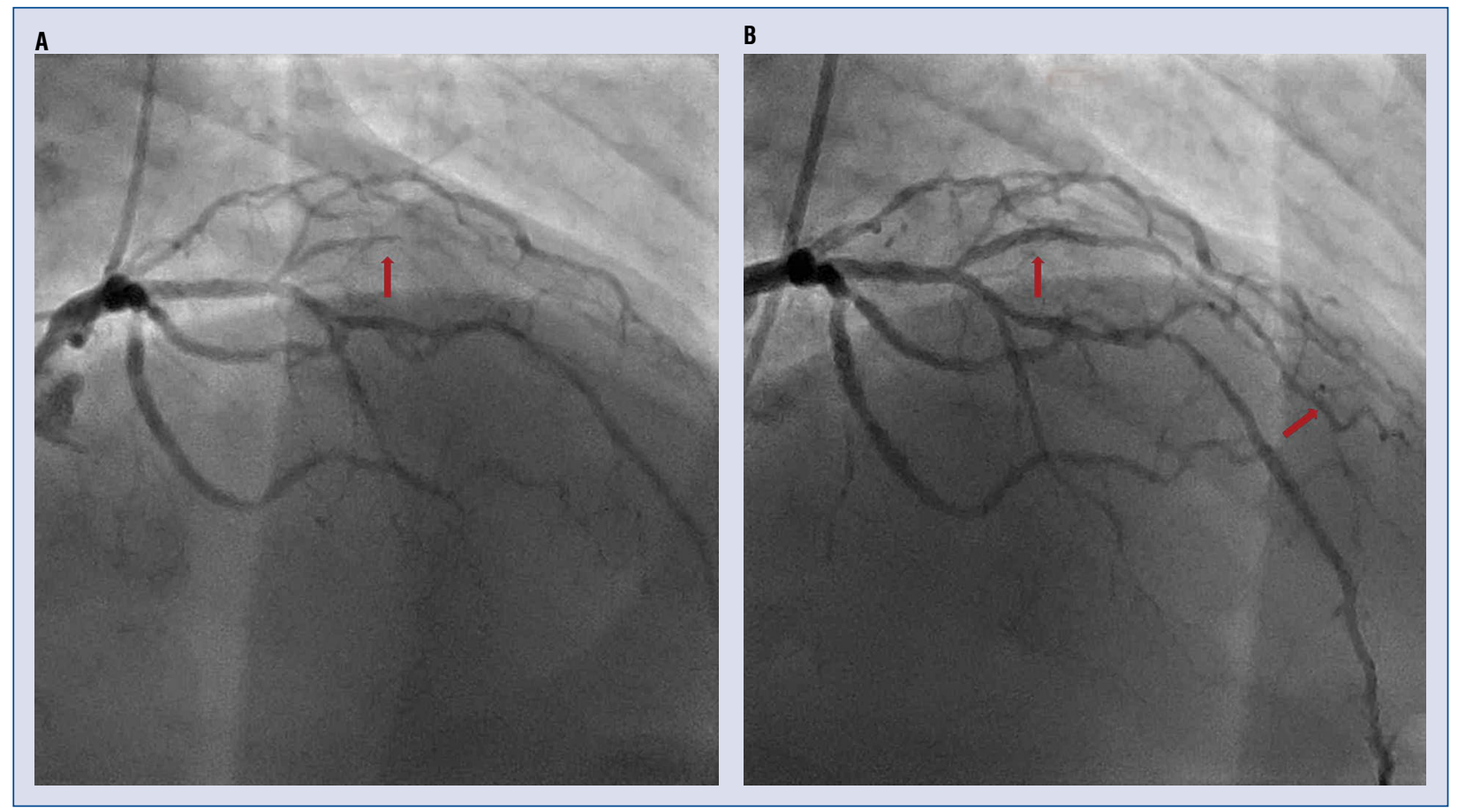

Figure 1. Example of small vessel disease amenable to percutaneous coronary intervention (RAO $\left.30^{\circ} ; \mathrm{CRA}^{\circ}\right)$. A. Acute occlusion of small $(1.5 \mathrm{~mm}$ ) diagonal branch (arrow); B. Final angiographic result; percutaneous coronary intervention with $2.0 \times 18 \mathrm{~mm}$ everolimus-eluting stent implantation in the proximal part of the vessel with slight oversize (left arrow); the image shows considerable length and extensive area supplied by the initially occluded vessel (right arrow).

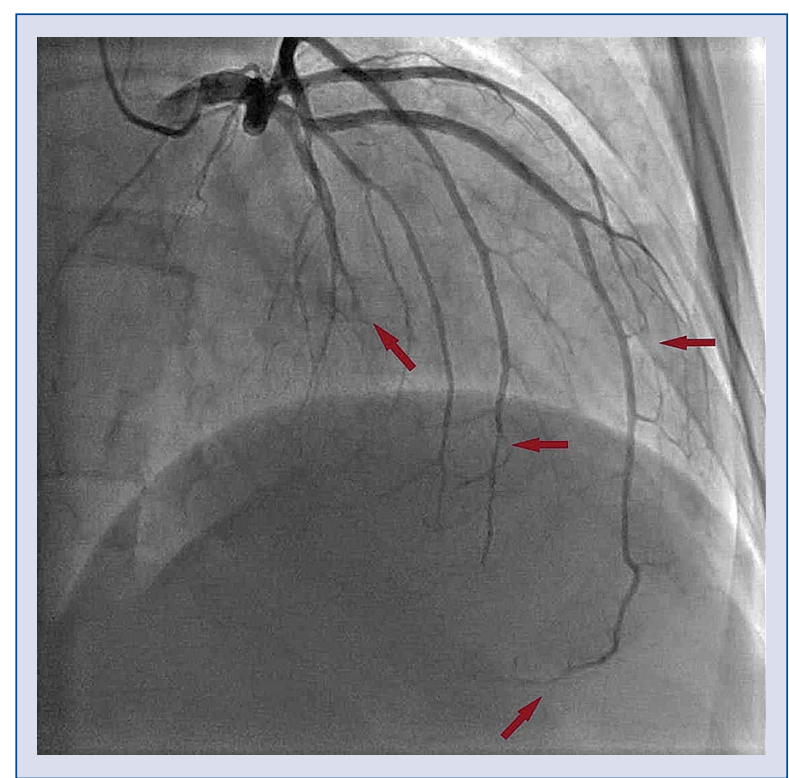

Figure 2. Example of diffuse small coronary artery atherosclerosis suitable for medical management (LAO $15^{\circ}$, CRA $30^{\circ}$ ); widespread significant lesions located predominantly in the peripheral and narrow parts of the coronary vessels (arrows).

impaired quality of life, and malignant ventricular arrhythmias [12]. On the other hand, an attempt of PCI may expose patients to the risk of coronary artery perforation, cardiac tamponade, and periprocedural myocardial infarction (MI) [13, 14]. However, the most important limitation of PCI in SVD is related with a higher rate of hemodynamically significant restenosis [15], which is primarily conditioned by lower initial lumen gain, rather than greater lumen loss as compared to PCI within vessels with larger diameter [2]. A large body of evidence suggests that smaller stent diameter suitable for SVD also constitutes a strong predictor of acute stent thrombosis (ST) [16]. Small stent diameter, along with increased total stent length and larger strut thickness, constitute powerful periprocedural predictors of long-term outcome [17].

The clinical profile of SVD patients, as well as higher rate of short- and long-term procedural complications, translates into poor long-term outcomes $[3,5]$. Despite the use of new-generation drug-eluting stents (DES), an accumulating body of evidence suggests that PCI of coronary arteries $<2.5 \mathrm{~mm}$ is associated with a high rate of target lesion failure (TLF) or cardiovascular death [5]. Given the clinical significance of SVD, in the present article we will attempt to summarize the current knowledge on the definition, different approaches to interventional management, and outcomes of small coronary artery atherosclerosis. 


\section{Methods}

This paper was based on systematic assessment of randomized controlled trials, observational and cohort studies, and meta-analyses comparing different strategies for the treatment of coronary stenoses located exclusively in small diameter vessels. The PubMed, EMBASE, Cochrane Library, and Clinical trial registries databases were searched using a combination of relevant text terms and key words: small coronary artery disease, small vessel coronary artery disease, small vessel disease, percutaneous coronary intervention, small coronary vessels, small coronary arteries, treatment, revascularization strategies, drug-coated balloons, drug-eluting stents, clinical trial, randomized trial, and meta-analysis. No language or sample size restrictions were applied. The review covered studies published between 1978 and April 2020.

\section{Definition and characteristics}

The greatest limitation of research in the field of SVD is the unclear definition of small coronary vessels used in the literature, which has evolved over the years. On the other hand, on closer examination, the small vessel diameter may be misleading and may derive from high plaque burden and diffuse disease.

Based on the meta-analysis by Agostoni et al. [18], SVD was liberally defined as atherosclerosis within the artery $<3.0 \mathrm{~mm}$. Also, the recent BASKET-SMALL 2 trial arbitrarily adopted the diameter threshold of $<3.0 \mathrm{~mm}$ as SVD [19]. Early trials progressively identified vessels $\leq 2.9 \mathrm{~mm}$ or $\leq 2.75 \mathrm{~mm}$ in diameter as SVD [20,21]. It is vital to note that these studies used these cut-off values as inclusion criteria, which were not validated against comparator cut-off values. A sub-study of the DUTCH-PEERS trial showed that a diameter of $2.5 \mathrm{~mm}$ appropriately stratifies patients in terms of risk of TLF [5]. Coronary arteries with diameter 2.5-3.0 were characterized by low risk of long-term complications as compared to vessels $>3.0 \mathrm{~mm}$. Conversely, the risk was far greater in vessels $<2.5 \mathrm{~mm}$ [5]. In the IRIS-DES registry, everolimus-eluting stent $<2.78 \mathrm{~mm}$ and biolimus-eluting stent $<3.20 \mathrm{~mm}$ corresponded with increased risk of composite endpoint of cardiac death, targetvessel MI, and revascularization [17]. Very small vessel CAD was defined by Biondi-Zoccai et al. [7]; the definition considers vessels amenable to intervention using a $2.25 \mathrm{~mm}$ balloon or stent.

One should take into consideration the fact that the impact of vessel diameter on prognosis, including the risk of in-stent restenosis (ISR) or $\mathrm{ST}$, is not categorical, and it should be regarded as a continuous variable (Fig. 3).

\section{Diagnostic work-up and indication for myocardial revascularization}

The decision-making process in patients with SVD should in general follow the same rules as described in European Society of Cardiology Guidelines for Myocardial Revascularization [22]. Depending on the clinical scenario, patients with acute coronary syndrome (ACS) should proceed to emergent invasive coronary angiography in cases of ST-segment elevation MI or non-ST-segment ACS with signs of hemodynamic or electrical instability or refractory angina. According to the guidelines on the management of chronic coronary syndromes (CCS), prior to invasive coronary angiography, all patients should be adequately verified in terms of the presence of ischemia using a non-invasive stress test [23].

\section{Functional assessment}

Prior to decision of myocardial revascularization, regardless of the vessel size, hemodynamic significance should be verified using fractional flow reserve (FFR) or instantaneous wave-free ratio measurements [24]. The PHANTOM trial provided evidence that purely angiographic assessment of SVD remains suboptimal and the use of functional assessment defers PCI in the majority of patients [25]. Only $30 \%$ of all SVD stenoses that had been alleged to be hemodynamically significant based on angiography alone were further confirmed to be truly significant [25]. Appropriate selection of affected vessels is crucial because of increased risk of long-term complications of PCI. Puymirat et al. [26] compared FFR-guided PCI with angiography-guided strategies in SVD and demonstrated a lower rate of target lesion revascularization (TLR), nonfatal MI, and major adverse cardiovascular events (MACE; $15 \%$ vs. $29 \%, \mathrm{p}=$ $=0.002)$ in patients treated with FFR-guided $\mathrm{PCI}$ as compared with angio-guided PCI. Procedural costs were also reduced in the FFR-guided strategy (€3253 \pm 102 vs. €4714 \pm 37 , p < $<0.0001$ ) [26]. In the angio-guided group, the number of vessels treated per patient was significantly higher, whereas minimal lumen diameter was significantly lower as compared with the FFR-guided group [26]. These data suggest that FFR improves clinical decision-making and outcome in SVD and reduces procedural costs. One of the possible drawbacks of this method is the possibility of distal 


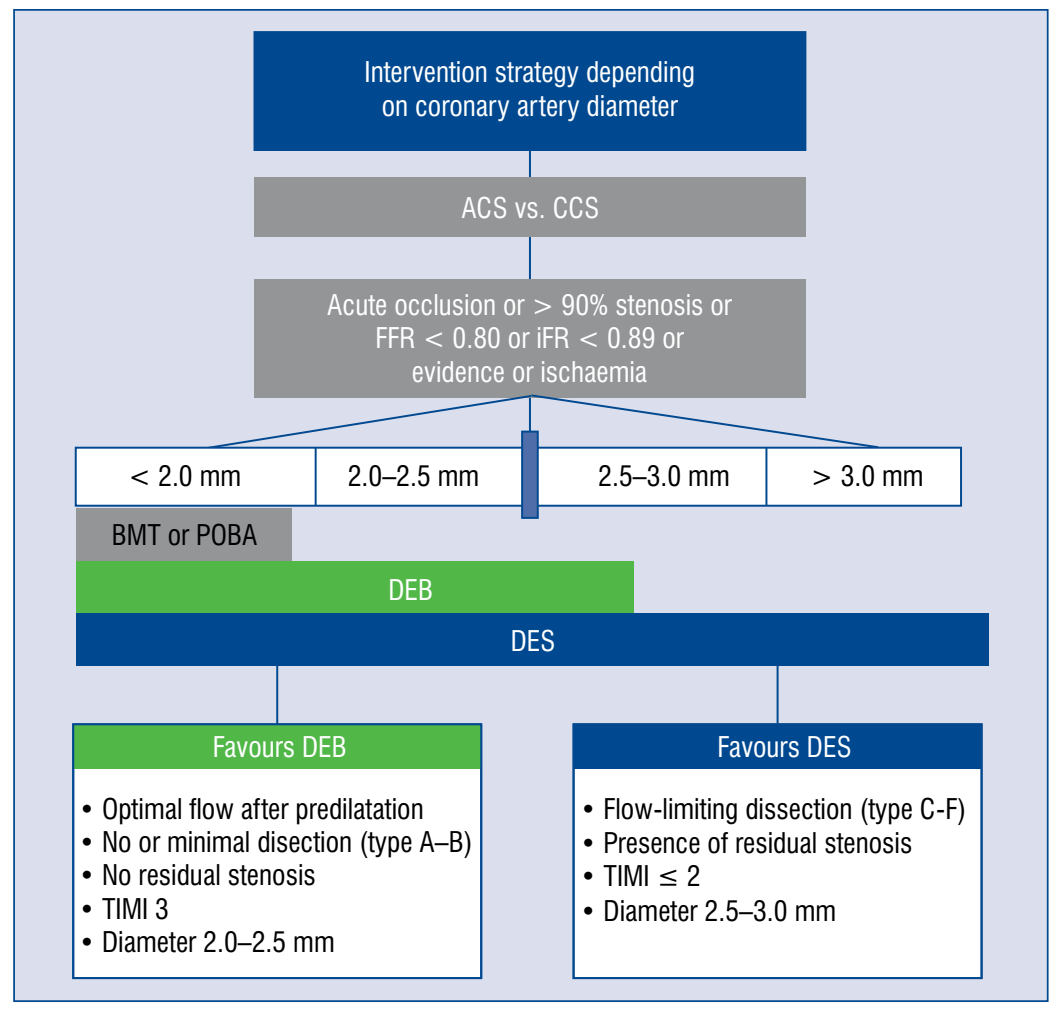

Figure 3. Classification of coronary arteries and the management of hemodynamically significant lesions depending on vessel diameter; SVD — small vessel disease; ACS — acute coronary syndrome; CCS — chronic coronary syndrome; FFR - fractional flow reserve; iFR — instantaneous wave-free ratio; BMT — best medical therapy; POBA — plain old balloon angioplasty; DEB — drug-eluting balloon; DES — drug-eluting stent; TIMI — Thrombolysis in Myocardial Infarction score.

perforation with the functional wire especially in small tortuous vessels.

Recently, a new quantitative flow ratio method of functional evaluation of coronary arteries was introduced, which is based on wire-free and adenosine-independent analysis of coronary angiography [27]. This promising new diagnostic tool was demonstrated to be as effective in vessels with diameter of $2.3-2.7 \mathrm{~mm}$ as in larger arteries with diameter 3.0-3.6 mm [28]. Similar technology based on non-invasive fractional flow reserve derived from computed tomography $\left(\mathrm{FFR}_{\mathrm{CT}}\right)$ has been introduced, but no data regarding its accuracy depending on vessel diameter have been published [29].

\section{Intravascular imaging}

Intravascular ultrasound (IVUS) is mostly recommended to guide revascularization of left main disease or in cases of stent-related complications [22]. Evidence on IVUS-guided PCI in SVD is less convincing, although one study suggested that it led to a reduction of the number and length of implanted stents, median stent diameter, and high-pressure balloon use [30]. Of note, the number of ISRs on 2-year follow-up and MACE was significantly lower in the IVUS-guided than in the angio-guided group [30].

The use of IVUS and optimal coherence tomography (OCT) is also decisive in the diagnosis of unusual causes of ACS, including spontaneous coronary dissection, intramural hematoma, coronary embolism and thrombosis, or angiographically missed eroded plaque. Some data show that precise OCT-based calculation of post-intervention minimal stent area $<3.5 \mathrm{~mm}^{2}$ in patients treated with a $2.5 \mathrm{~mm}$ everolimus-eluting stent predicts the 9 -month risk of ISR [31]. Nevertheless, the use of IVUS and OCT in vessels $<2.25 \mathrm{~mm}$ may be challenging and increases the risk of iatrogenic plaque destabilization, coronary dissection, thrombosis, and coronary perforation [32].

\section{Options of myocardial revascularization}

The final decision about the revascularization should depend on the symptomatic presentation. The primary goal of PCI of narrow and frequently 
peripheral coronary arteries in CCS patients is to provide symptomatic relief. This belief was endorsed by recently presented results of the pivotal ISCHEMIA trial (International Study of Comparative Health Effectiveness With Medical and Invasive Approaches) [33], which compared an invasive strategy with conservative pharmacological management of patients with moderate-severe ischemia based on non-invasive stress test [33]. The study showed that in a median follow-up time of 3.3 years, patients treated conservatively had similar outcomes to patients managed invasively, as reflected by comparable rates of composite endpoint of death, MI, resuscitated cardiac arrest, hospitalization for unstable angina, or heart failure (15.5\% vs. $13.3 \%, \mathrm{p}=0.34)$ [33]. Nonetheless, the invasive group was characterized by significant reduction of symptoms, but only if angina was present at baseline [33]. This landmark trial provided sound evidence for a more lenient approach to revascularization in CCS, especially in patients with peripheral SVD.

In cases of ACS, PCI or coronary artery bypass grafting (CABG) should generally be pursued, which is addressed in subsequent sections of the manuscript. It should be noted, however, that some evidence adjudicates in favor of conservative management in very specific clinical situations. In the EROSION study Jia et al. [34] found that antithrombotic therapy without stenting is a reasonable clinical option, provided that plaque erosion (not rupture) has been confirmed in OCT imaging. This was confirmed by reduction of thrombus burden or its disappearance on OCT at 1-month [34] and 12-month follow-up [35]. It is vital to note that nearly $25 \%$ of all patients presented with this etiology of ACS [34], which may be regarded as a rationale for conservative management of patients with ACS due to eroded plaque in small vessels, especially if the PCI is at risk because of small vessel diameter.

\section{Plain old balloon angioplasty}

Since the beginning of invasive cardiology, PCI has evolved from plain old balloon angioplasty (POBA) and bare-metal stents (BMS) to drugcoated balloons (DCB) and drug-eluting stents (DES), which result in better clinical outcomes [36]. Although POBA should be regarded as a viable option within coronary arteries $<2.0 \mathrm{~mm}$ (Fig. 3), in which stent implantation is technically impossible or could increase the risk of vessel rupture, a number of studies have proven that stent implantation confers significantly lower risk of restenosis as compared with POBA [7, 18]. According to some reports, balloon-only PCI with optimal postprocedural angiographic flow can achieve comparable results to BMS implantation in small coronary vessels [18].

Technological development has led to the introduction of commonly available $1.5 \mathrm{~mm}$ or even smaller balloons; however, no prospective data on the results of POBA with this kind of device are available. Examples of the smallest balloons include the $1.5 \mathrm{~mm} \mathrm{APEX}{ }^{\circledR}$ Dilatation Catheter [37], 1.25 Sprinter ${ }^{\circledR}$ Legend RX, $1.5 \mathrm{~mm}$ Euphora ${ }^{\circledR}$ Semicompliant Dilatation Catheter [38], $1.0 \mathrm{~mm}$ Ryurei ${ }^{\circledR}$ Dilatation Catheter [39], and 1.25 Sapphire ${ }^{\circledR}$ Coronary Dilatation Catheter [40], which are dedicated to dilatation of the most stenotic part of the lesion. The even smaller $0.85 \mathrm{~mm}$ NIC Nano balloon was introduced for PCI of chronic total occlusion [41]. All the above-mentioned balloon catheters share different technical specifications, and an overview is beyond the scope the current manuscript. Nowadays these dilatation catheters are primarily used for stepped lesion preparation prior to stenting of larger coronary arteries. Randomized controlled trials are warranted to assess the safety and feasibility of these devices for POBA in SVD.

\section{BMS and DES}

Stent implantation has become the core element of PCI in the majority of procedures, including SVD [18]. Accordingly, with the advent of DES showing better efficacy in terms of lower rates of ISR and TLR, combarable risk of ST and mortality, second-generation DES implantation is the stateof-the-art management of patients with $\mathrm{CAD}$ within vessels large enough to accommodate a stent [42]. Although the ISR rate has generally diminished, the efficacy of DES within small coronary arteries is lower [43, 44]. A wall injury induced by stent implantation initiates a vasculoproliferative cascade with smooth muscle cell proliferation and neointimal hyperplasia [45]. This protrusion is independent of nominal vessel size, so smaller coronary arteries are more prone to late luminal loss and are less able to accommodate neointimal tissue without blood flow limitation [46, 47]. The DUTCH PEERS randomized trial assessed novel DES (zotarolimus and everolimus) in patients with SVD [5]. The rates of TLF were significantly higher in patients with target lesion being $<2.5 \mathrm{~mm}$ than in those that were $\geq 2.5 \mathrm{~mm}(8.6 \%$ vs. $5.4 \%, \mathrm{p}=$ $=0.01$ ), and acute myocardial infarction (AMI) was numerically, but not significantly, higher (2.7\% vs. $1.2 \%, \mathrm{p}=0.04$ ) [5]. Another study with a sirolimus- 
Table 1. Overview of available evidence concerning percutaneous coronary interventions of small coronary vessels.

\begin{tabular}{|c|c|c|c|c|c|}
\hline Trial & Type & $\begin{array}{l}\text { Sample } \\
\text { size }\end{array}$ & $\begin{array}{c}\text { Reference } \\
\text { diameter }[\mathrm{mm}]\end{array}$ & Intervention & $\begin{array}{l}\text { Target lesion } \\
\text { revascularization }\end{array}$ \\
\hline \multicolumn{6}{|l|}{ BMS vs. POBA } \\
\hline LASMAL I [76] & RCT & 246 & $2.0-2.9$ & BMS vs. POBA & $0.8 \%$ vs. $6.6 \%, p=0.018$ \\
\hline \multicolumn{6}{|l|}{ DES vs. BMS } \\
\hline C-SIRIUS [49] & $\mathrm{RCT}$ & 100 & $2.5-3.0$ & SES vs. BMS & $4 \%$ vs. $18 \%, p=0.05$ \\
\hline SES-SMART [21] & $\mathrm{RCT}$ & 257 & $\leq 2.75$ & SES vs. BMS & $9.8 \%$ vs. $53.1 \%, p<0.001$ \\
\hline E-SIRIUS [77] & $\mathrm{RCT}$ & 352 & $2.5-3.0$ & SES vs. BMS & $4 \%$ vs. $20.9 \%, p<0.0001$ \\
\hline \multicolumn{6}{|l|}{ DES vs. DES } \\
\hline ISAR-SMART 3 [78] & RCT & 360 & $<2.8$ & PES vs. SES & $14.7 \%$ vs. $6.6 \%, p=0.008$ \\
\hline \multicolumn{6}{|c|}{ DCB vs. POBA/BMS/DES } \\
\hline PICCOLETO [79] & $\mathrm{RCT}$ & 57 & $\leq 2.75$ & DCB vs. PES & $10.3 \%$, vs. $32.1 \%, p=0.043$ \\
\hline BELLO [63] & $\mathrm{RCT}$ & 182 & $<2.8$ & DCB vs. PES & $4.4 \%$ vs. $7.6 \%, p=0.37$ \\
\hline BASKET-SMALL 2 [19] & RCT & 758 & $<3.0$ & DCB vs. DES & $3.4 \%$ vs. $4.5 \%, p=0.4375$ \\
\hline Giannini et al. [64] & $\begin{array}{l}\text { Cohort } \\
\text { study }\end{array}$ & 181 & $<2.8$ & DCB vs. EES & $4.4 \%$ vs. $5.6 \%, p=0.720$ \\
\hline Sim et al. [80] & $\begin{array}{l}\text { Cohort } \\
\text { study }\end{array}$ & 87 & 2.0 & DCB vs. DES & $7.0 \%$ vs. $8.2 \%, p=0.73$ \\
\hline Nishiyama et al. [81] & RCT & 60 & $<3.0$ & DCB vs. DES & $0.0 \%$ vs. $6.1 \%, p=0.169$ \\
\hline Funatsu et al. [82] & RCT & 135 & $<2.8$ & DCB vs. POBA & $2.3 \%$ vs. $10.3 \%, p=0.07$ \\
\hline Her et al. [83] & $\begin{array}{l}\text { Case-con- } \\
\text { trol study }\end{array}$ & 72 & $2.5-3.0$ & DCB vs. POBA & $0 \%$ vs. $13 \%, p=0.033$ \\
\hline Sinaga et al. [65] & $\begin{array}{l}\text { Case-con- } \\
\text { trol study }\end{array}$ & 335 & $\leq 2.5$ & DCB vs. DES & $5.2 \%$ vs. $3.7 \%, p=0.601$ \\
\hline Shin et al. [84] & $\begin{array}{l}\text { Cohort } \\
\text { study }\end{array}$ & 66 & $<3.0$ & DCB vs. DES/BMS & $0 \%$ vs $5 \%, p=N S$ \\
\hline RESTORE SVD [66] & $\mathrm{RCT}$ & 256 & $2.0-2.75$ & DCB vs. ZES & 2 years: $5.2 \%$ vs. $2.8 \%, p=0.5$ \\
\hline SCAAR Report [67] & $\begin{array}{l}\text { Cohort } \\
\text { study }\end{array}$ & 14,788 & $\leq 2.5$ & DCB vs. DES & $4.1 \%$ vs. $1.8 \%, p<0.001$ \\
\hline
\end{tabular}

DCB — drug-coated balloon; DES — drug-eluting stent; POBA — plain old balloon angioplasty; RCT — randomized controlled trial; BMS - bare metal stent; EES - everolimus-eluting stent; PES — paclitaxel-eluting stent; SES — sirolimus-eluting stent;

ZES - zotarolimus-eluting stent

eluting stent (SES) and angiographic follow-up showed higher restenosis rates in patients with lesions smaller than $2.41 \mathrm{~mm}$, as compared with those over $\geq 2.41 \mathrm{~mm}[48]$.

The current evidence regarding the use of BMS/DES is summarized in Table 1. According to the C-SIRUS trial, deployment of SES instead of BMS has improved TLR from $52 \%$ to only $2 \%$ [49]. Similar results were confirmed in other trials with a very low late loss ranging between 0.05 and $0.20 \mathrm{~mm}[21,48,49]$. Moreover, the median TLR rate was $7 \%$ for SES in comparison to $15 \%$ and $13 \%$ for a paclitaxel-eluting stent (PES) and DCB, respectively [50]. SES significantly reduced the odds of TLR compared to PES (odds ratio [OR] 0.39), DCB (OR 0.34) and BMS (OR 0.21), but there were no differences in the rate of AMIs among patients [50].

Factors such as lesion length, strut thickness, and minimum stent lumen diameter were identified as independent predictors of restenosis in DES [45, $51,52]$. The most powerful predictor of angiographic restenosis is the diameter of the vessel, with a $60 \%$ higher risk of restenosis for each decrease by 0.50 mm [53]. The TAXUS ATLAS study compared the performance of the thin strut $(0.095 \mathrm{~mm})$ Taxus Liberte $2.25 \mathrm{~mm}$ stent and the Taxus Express $(0.132$ $\mathrm{mm})$ in small vessels [54]. Thinner stent struts significantly reduced the rate of 9 -month restenosis ( $18.5 \%$ vs. $32.7 \%, \mathrm{p}=0.02)$ [54].

Technological development led to the introduction of $2.0 \mathrm{~mm}$ stents in order to accommodate 
Table 2. Principles of percutaneous coronary intervention with drug-coated balloons (DCB) [60,62].

1. The lesion should be prepared prior to the use of DCB. DCB should serve only as a vector of antiproliferative drug.

2. Predilatation with semi-compliant balloon sized $0.8-1.0$ to reference vessel diameter with higher than nominal pressure.

3. Use of non-compliant balloons or scoring/cutting balloons or rotablation in the case of complex lesions.

4. Prior to using DCB, check the deliverability of DCB to peripheral lesions. Severe proximal calcifications can prevent the transfer of DCB to the culprit lesion.

5. DCB should not be applied in lesions with residual stenosis $>30 \%$ or with type $\mathrm{C}-\mathrm{F}$ dissection following initial predilatation. Consider DES implantation.

6. DCB should not be exposed to or immersed into the saline as the drug can be released in the solvent, not the culprit lesion.

7. DCB should be swiftly deployed in the lesion, as the drug can be dissolved in the catheter or in non-culprit segment of the artery.

8. DCB should be sized $0.8-1.0$ to reference vessel diameter and inflated for at least 30-60 s depending on the DCB type.

9. Angiographic or intravascular assessment of possible complications (dissection).

10. Dual antiplatelet therapy for as little as 1 month in patients with chronic coronary syndrome.

for smaller vessel size, but the clinical benefit of small stent implantation $(\leq 2.25 \mathrm{~mm})$ is vague [55]. The new portfolio of $2.0 \mathrm{~mm}$ DES (everolimus-eluting Xience Xpedition SV or Xience Alpine; zotarolimus-eluting Resolute Onyx) created new options of PCI in a smaller vascular territory, with promising results in retrospective analysis $[55,56]$.

\section{Drug-coated balloons}

Drug-coated balloon therapy (otherwise known as drug-eluting balloon, DEB) has been proposed as an alternative to DES in SVD, obviating the need for implantation of a foreign body into a small artery [57]. The technique is based on rapid delivery of an antiproliferative drug to the arterial wall from a semi-compliant balloon covered with a lipophilic matrix [58]. Therapeutic agents, most commonly paclitaxel, are delivered during single balloon inflation, which should last between 30 and 60 seconds depending on the $\mathrm{DCB}$ type [58]. A crucial step prior to deployment of DCB consists of adequate lesion preparation with a successful predilatation to avoid elastic recoil and flow-limiting dissections [59]. It was shown to provide a good initial angiographic result [59]. The basic principles of PCI with the use of DCB are highlighted in Table 2 [60].

In the past, $\mathrm{DCB}$ was primarily utilized for the treatment of ISR, which constitutes its primary indication with class IA recommendation in line with current European Society of Cardiology Guidelines on Myocardial Revascularization [22, 61]. How- ever, numerous recent studies have focused on the possible application of DCB for the treatment of de-novo lesions within small coronary arteries. A few randomized controlled trials compared the efficacy of DCB and DES in SVD. A summary of available evidence concerning the comparison of $\mathrm{DCB}$ and DES in SVD is presented in Table 1 [62].

The results of the BELLO study are worth mentioning, which compared the IN.PACT Falcon paclitaxel-coated balloon with PES Taxus Liberte in vessels with a mean diameter of $2.15 \mathrm{~mm}$ [63]. The study showed promising lower late lumen in the DCB group than in the PES group $(0.08 \mathrm{~mm}$ vs. $0.29 \mathrm{~mm}, \mathrm{p}<0.001)$, but similar event rates were reported in both groups [63]. This was confirmed in propensity score analysis of the BELLO population [64].

More recently Sinaga et al. [65] performed a retrospective analysis of 335 patients treated either with DCB or DES by means of device $\leq 2.5 \mathrm{~mm}$. This real-world analysis showed that although the DCB group had lower acute lumen gain than DES group, the 1 -year MACE rate $(11.6 \%$ vs. $11.7 \%$, $\mathrm{p}=1.0)$ and TLR $(5.2 \%$ vs. $3.7 \%, \mathrm{p}=0.601)$ were comparable between both cohorts [65].

Similar efficacy between DCB and DCB within relatively small coronary vessels was further corroborated by the high-volume BASKET-SMALL 2 study [19]. This open-label randomized trial comprised 758 patients with native lesions in vessels $<3.0 \mathrm{~mm}$ to either DCB or second-generation DES implantation [19]. The use of DCB was non-inferior 
to second-generation DES in terms of MACE occurrence (cardiovascular death, non-fatal AMI, target vessel revascularization) at 12 months (7.5\% vs. $7.3 \%$, hazard ratio [HR] $0.97, p=0.918$ ) [19].

Also, the RESTORE SVD randomized trial compared DCB with zotarolimus-eluting stent in 256 patients with de novo lesions within vessels between 2.0 and $2.75 \mathrm{~mm}$ in size [66]. TLF did not differ significantly between DCB and DES group at 2 years $(5.2 \%$ vs. $3.7 \%, \mathrm{p}=0.75)$ [66].

In contrast to former reports, doubt was cast on the efficacy of DCB in de novo SVD in the recent SCAAR report [67]. This retrospective registry-based Swedish study comprised 14,788 patients treated with either DCB or second-generation DES for stenoses in arteries $\leq 2.5 \mathrm{~mm}$ [67]. The propensity score-matched analysis denoted that the DCB group was characterized by significantly higher risk of restenosis at 3 years (HR 2.027, 95\% confidence interval [CI] 1.537-2.674) but had comparable risk of lesion thrombosis, AMI, and all-cause death to the DES group [67]. Despite its retrospective design, the present study is the largest report concerning SVD treatment with DCB. Further high-volume prospective studies are required to verify the conflicting results of the trials.

In spite of divergent data on risk of restenosis [19, 67], DCB represents a viable interventional option in patients with native SVD, with similar risk of adverse events and mortality to contemporary DES technology. The advantages of DCB over stent implantation include significantly lower risk of acute thrombosis, potentially favorable vascular remodeling after PCI, and dual antiplatelet therapy shortened to 4 weeks in stable patients, which may reduce the risk of major bleeding and bring additional clinical benefit [19]. DCB should be applied particularly within in-stent restenosis, in de novo lesions ranging from $2.0 \mathrm{~mm}$ to $2.5 \mathrm{~mm}$, and as an adjunct to DES implantation for side branch PCI in selected cases (Fig. 3) [68].

\section{Bioresorbable scaffolds}

Bioresorbable scaffolds (BRS) were designed to allow for gradual resorption of stent components, which seemed to be attractive in the context of possible PCI in SVD [69]. This approach was thought to provide similar benefits as DES, at same time being minimally invasive. Conversely, the firstgeneration lactic acid BRS was shown to confer greater risk of subacute, late, and very late stent thrombosis and a higher rate of TLR, most likely due to the design of thick lactic acid struts $[70,71]$. This led to contraindication for these devices to be used in routine clinical practice outside of clinical trials and recommendation for prolonged dual antiplatelet therapy $>12$ months [21]. The potential benefit of these stents in SVD was outweighed by even greater risk of poor outcome within small coronary vessels [72]. The retrospective analysis by Wiebe et al. [72] provided evidence that implantation of the smallest $2.5 \mathrm{~mm}$ BRS was linked to higher risk of TLF (HR 1.31, 95\% CI 1.01-1.69). There are numerous ongoing trials evaluating the application of experimental bioresorbable technologies, including magnesium-based bioresorbable stents [73]. Time will show if these solutions are safe in the clinical setting of SVD.

\section{CABG}

Coronary artery bypass grafting represents a cornerstone of myocardial revascularization in patients with multivessel CAD and high SYNTAX score [74]. Multivessel CAD is frequently accompanied by the presence of SVD. Based on convincing evidence from high-volume reports, CABG is not a preferable choice of treatment in SVD due to an increased risk of technical failure and risk of MACE [75]. O'Connor et al. [75] studied the impact of gender, body size, and mid-left anterior descending artery dimeter on the in-hospital mortality of patients submitted to CABG [76]. The in-hospital mortality amounted to $15.8 \%$ in patients with a diseased vessel diameter of $1.0 \mathrm{~mm}$, while it was as low as $1.5 \%$ in patients with a grafted vessel size of 2.5-3.5 mm [75]. This constitutes a strong indicator that vessel size should be regarded as one of the core variables in the decision-making process during Heart Team meetings. Unfortunately, the reference tool for evaluation of morphology and degree of CAD, namely the SYNTAX score, does not account for vessels $<1.5 \mathrm{~mm}$ and it does adjust risk score to vessel diameter in larger arteries, which represents a major limitation of the current approach [74].

\section{Conclusions}

Small vessel disease is a challenging condition due to its equivocal definition and abundance of different therapeutic options. Revascularization should be performed in patients with confirmed ischemia and only in cases of hemodynamically significant lesions based on functional assessment, which has proven even more important in small vessel diameter. The diameter of the diseased vessel represents the most potent variable affecting long-term outcome after PCI in SVD. The choice 
between DES or DCB should be based on a number of clinical variables, including vessel size, ischemic territory, and lesion characteristics. In the group of lesions $>2.5 \mathrm{~mm}$, the application of DES is associated with a more favorable clinical outcome with low rate of TLR, while both DCB and DES tend to show similar efficacy in the vessel diameter between 2.0 and $2.5 \mathrm{~mm}$. In this clinical setting, DCB is an alternative to DES, with the advantage of positive vascular remodeling and shortened dual antiplatelet therapy. Very small coronary vessels $<2.0 \mathrm{~mm}$ should either be treated with POBA or best medical therapy, especially in the case of chronic coronary syndromes. SVD remains an unexplored clinical setting, which requires extensive research into the indications and optimal methods of myocardial revascularization.

\section{Conflict of interest: None declared}

\section{References}

1. Biondi-Zoccai G, Sangiorgi G, Antoniucci D, et al. Testing prospectively the effectiveness and safety of paclitaxel-eluting stents in over 1000 very high-risk patients. Int J Cardiol. 2007; 117(3): 349-354, doi: 10.1016/j.ijcard.2006.05.018.

2. Akiyama T, Moussa I, Reimers B, et al. Angiographic and clinical outcome following coronary stenting of small vessels: a comparison with coronary stenting of large vessels. J Am Coll Cardiol. 1998; 32(6): 1610-1618, doi: 10.1016/s0735-1097(98)00444-6, indexed in Pubmed: 9822086.

3. Scholz SS, Lauder L, Ewen S, et al. One-year clinical outcomes in patients with renal insufficiency after contemporary PCI: data from a multicenter registry. Clin Res Cardiol. 2020; 109(7): 845-856, doi: 10.1007/s00392-019-01575-y, indexed in Pubmed: 31792571.

4. Elezi S, Kastrati A, Neumann FJ, et al. Vessel size and longterm outcome after coronary stent placement. Circulation. 1998; 98(18): 1875-1880, doi: 10.1161/01.cir.98.18.1875.

5. van der Heijden LC, Kok MM, Danse PW, et al. Small-vessel treatment with contemporary newer-generation drug-eluting coronary stents in all-comers: Insights from 2-year DUTCH PEERS (TWENTE II) randomized trial. Am Heart J. 2016; 176: 28-35, doi: 10.1016/j.ahj.2016.02.020, indexed in Pubmed: 27264217.

6. Briguori C, Tobis J, Nishida T, et al. Discrepancy between angiography and intravascular ultrasound when analysing small coronary arteries. Eur Heart J. 2002; 23(3): 247-254, doi: 10.1053/ euhj.2001.2730, indexed in Pubmed: 11792140.

7. Biondi-Zoccai G, Moretti C, Abbate A, et al. Percutaneous coronary intervention for small vessel coronary artery disease. Cardiovasc Revasc Med. 2010; 11(3): 189-198, doi: 10.1016/j. carrev.2009.04.007, indexed in Pubmed: 20599174.

8. Dortimer AC, Shenoy PN, Shiroff RA, et al. Diffuse coronary artery disease in diabetic patients: fact or fiction? Circulation. 1978; 57(1): 133-136, doi: 10.1161/01.cir.57.1.133, indexed in Pubmed: 618380.
9. Mosseri M, Yarom R, Gotsman MS, et al. Histologic evidence for small-vessel coronary artery disease in patients with angina pectoris and patent large coronary arteries. Circulation. 1986; 74(5): 964-972, doi: 10.1161/01.cir.74.5.964, indexed in Pubmed: 3769180.

10. Acharjee S, Teo KK, Jacobs AK, et al. COURAGE Trial Research Group. Optimal medical therapy with or without PCI for stable coronary disease. N Engl J Med. 2007; 356(15): 1503-1516, doi: 10.1056/NEJMoa070829, indexed in Pubmed: 17387127.

11. Ong P, Safdar B, Seitz A, et al. Diagnosis of coronary microvascular dysfunction in the clinic. Cardiovasc Res. 2020; 116(4): 841-855, doi: 10.1093/cvr/cvz339, indexed in Pubmed: 31904824.

12. Ford TJ, Corcoran D, Berry C. Stable coronary syndromes: pathophysiology, diagnostic advances and therapeutic need. Heart. 2018; 104(4): 284-292, doi: 10.1136/heartjnl-2017-311446, indexed in Pubmed: 29030424.

13. Rogers JH, Lasala JM. Coronary artery dissection and perforation complicating percutaneous coronary intervention. J Invasive Cardiol. 2004; 16(9): 493-499, indexed in Pubmed: 15353832.

14. Ndrepepa G, Berger P, Mehilli J, et al. Periprocedural bleeding and 1-year outcome after percutaneous coronary interventions. J Am Coll Cardiol. 2008; 51(7): 690-697, doi: 10.1016/j. jacc.2007.10.040.

15. Rathore S, Terashima M, Katoh O, et al. Predictors of angiographic restenosis after drug eluting stents in the coronary arteries: contemporary practice in real world patients. EuroIntervention. 2009; 5(3): 349-354, doi: 10.4244/v5i3a55, indexed in Pubmed: 19736160.

16. Brodie B, Pokharel Y, Garg A, et al. Predictors of early, late, and very late stent thrombosis after primary percutaneous coronary intervention with bare-metal and drug-eluting stents for ST-segment elevation myocardial infarction. JACC Cardiovasc Interv. 2012; 5(10): 1043-1051, doi: 10.1016/j.jcin.2012.06.013, indexed in Pubmed: 23078734.

17. Lee CH, Kang DY, Han M, et al. IRIS-DES Registry Investigators. Differential cutoff points and clinical impact of stent parameters of various drug-eluting stents for predicting major adverse clinical events: An individual patient data pooled analysis of seven stent-specific registries and 17,068 patients. Int J Cardiol. 2019; 282: 17-23, doi: 10.1016/j.ijcard.2019.01.108, indexed in Pubmed: 30745256.

18. Agostoni P, Biondi-Zoccai GGL, Gasparini GL, et al. Is baremetal stenting superior to balloon angioplasty for small vessel coronary artery disease? Evidence from a meta-analysis of randomized trials. Eur Heart J. 2005; 26(9): 881-889, doi: 10.1093/ eurheartj/ehi116, indexed in Pubmed: 15681573.

19. Jeger RV, Farah A, Ohlow MA, et al. BASKET-SMALL 2 Investigators. Drug-coated balloons for small coronary artery disease (BASKET-SMALL 2): an open-label randomised non-inferiority trial. Lancet. 2018; 392(10150): 849-856, doi: 10.1016/S01406736(18)31719-7, indexed in Pubmed: 30170854.

20. Doucet S, Schalij MJ, Vrolix MC, et al. Stent In Small Arteries (SISA) Trial Investigators. Stent placement to prevent restenosis after angioplasty in small coronary arteries. Circulation. 2001; 104(17): 2029-2033, indexed in Pubmed: 11673341.

21. Ardissino D, Cavallini C, Bramucci E, et al. Sirolimus-Eluting vs uncoated stents for prevention of restenosis in small coronary arteries. JAMA. 2004; 292(22): 2727, doi: 10.1001/ jama.292.22.2727.

22. Neumann FJ, Sousa-Uva M, Ahlsson A, et al. ESC Scientific Document Group. 2018 ESC/EACTS Guidelines on myocardial 
revascularization. Eur Heart J. 2019; 40(2): 87-165, doi: 10.1093/ eurheartj/ehy394, indexed in Pubmed: 30165437.

23. Knuuti J, Wijns W, Saraste A, et al. ESC Scientific Document Group. 2019 ESC Guidelines for the diagnosis and management of chronic coronary syndromes. Eur Heart J. 2020; 41(3): 407-477, doi: 10.1093/eurheartj/ehz425, indexed in Pubmed: 31504439.

24. Hau WK. Fractional flow reserve and complex coronary pathologic conditions. Eur Heart J. 2004; 25(9): 723-727, doi: 10.1016/j. ehj.2004.02.019, indexed in Pubmed: 15120881.

25. Costa MA, Sabate M, Staico R, et al. Anatomical and physiologic assessments in patients with small coronary artery disease: final results of the Physiologic and Anatomical Evaluation Prior to and After Stent Implantation in Small Coronary Vessels (PHANTOM) trial. Am Heart J. 2007; 153(2): 296.e1-296.e7, doi: 10.1016/j.ahj.2006.10.036, indexed in Pubmed: 17239692.

26. Puymirat E, Peace A, Mangiacapra F, et al. Long-term clinical outcome after fractional flow reserve-guided percutaneous coronary revascularization in patients with small-vessel disease. Circ Cardiovasc Interv. 2012; 5(1): 62-68, doi: 10.1161/CIRCINTERVENTIONS.111.966937, indexed in Pubmed: 22319067.

27. Tu S, Westra J, Yang J, et al. Diagnostic Accuracy of Fast Computational Approaches to Derive Fractional Flow Reserve From Diagnostic Coronary Angiography. JACC: Cardiovascular Interventions. 2016; 9(19): 2024-2035, doi: 10.1016/j.jcin.2016.07.013.

28. Erbay A, Steiner J, Lauten A, et al. Assessment of intermediate coronary lesions by fractional flow reserve and quantitative flow ratio in patients with small-vessel disease. Catheter Cardiovasc Interv. 2019 [Epub ahead of print], doi: 10.1002/ccd.28531, indexed in Pubmed: 31631499.

29. Zhuang B, Wang S, Zhao S, et al. Computed tomography angiography-derived fractional flow reserve (CT-FFR) for the detection of myocardial ischemia with invasive fractional flow reserve as reference: systematic review and meta-analysis. Eur Radiol. 2020; 30(2): 712-725, doi: 10.1007/s00330-019-06470-8, indexed in Pubmed: 31696294.

30. Li L, Wang Li, Zhai CJ, et al. Clinical utility of intravascular ultrasonography-guided therapy in a small-vessel coronary lesion associated with Type 2 diabetes mellitus. Anatol J Cardiol. 2019; 22(2): 68-76, doi: 10.14744/AnatolJCardiol.2019.77009, indexed in Pubmed: 31375651.

31. Matsuo Y, Kubo T, Aoki H, et al. Optimal threshold of postintervention minimum stent area to predict in-stent restenosis in small coronary arteries: An optical coherence tomography analysis. Catheter Cardiovasc Interv. 2016; 87(1): E9-E14, doi: 10.1002/ccd.26143, indexed in Pubmed: 26268150.

32. Kordish I, Philipp S, Boese D, et al. [Dissection of the right coronary artery as a complication after the IVUS procedure]. Herz. 2007; 32(7): 573-577, doi: 10.1007/s00059-007-2900-8, indexed in Pubmed: 17972031.

33. Judith S. Hochman at the American Heart Association Annual Scientific Sessions (AHA 2019). Philadelphia, PA, November, $16,2019$.

34. Jia H, Dai J, Hou J, et al. Effective anti-thrombotic therapy without stenting: intravascular optical coherence tomography-based management in plaque erosion (the EROSION study). Eur Heart J. 2017; 38(11): 792-800, doi: 10.1093/eurheartj/ehw381, indexed in Pubmed: 27578806.

35. Xing L, Yamamoto E, Sugiyama T, et al. EROSION Study (Effective Anti-Thrombotic Therapy Without Stenting: Intravascular Optical Coherence Tomography-Based Management in Plaque
Erosion): A 1-Year Follow-Up Report. Circ Cardiovasc Interv. 2017; 10(12), doi: 10.1161/CIRCINTERVENTIONS.117.005860, indexed in Pubmed: 29246916.

36. Yano H, Horinaka S, Ishikawa M, et al. Efficacy of everolimuseluting stent implantation in patients with small coronary arteries $(\leq 2.5 \mathrm{~mm})$ : outcomes of 3-year clinical follow-up. Heart Vessels. 2017; 32(7): 796-803, doi: 10.1007/s00380-016-0937-4, indexed in Pubmed: 28025695.

37. https://www.bostonscientific.com/en-US/products/catheters-balloon/apex-ptca-dilatation-catheter.html (Date of entry: 30.03.2020).

38. https://www.medtronic.com/us-en/healthcare-professionals/ products/cardiovascular/coronary-balloons/sprinter-legend-rxsemicompliant.html (Date of entry: 30.03.2020).

39. https://www.terumo-europe.com/en-emea/products/ ryurei\%E2\%84\%A2-ptca-dilatation-catheter (Date of entry: 30 ).

40. https://www.orbusneich.com/en/products/semi-compliant-balloons/sapphire (Date of entry: 30.03.2020).

41. https://www.sis-medical.com/nic-nano-0-85-cto-balloon (Date of entry: 30.03.2020).

42. Lee P, Kwon O, Ahn JM, et al. Safety and effectiveness of secondgeneration drug-eluting stents in Patients with left main coronary artery disease. J Am Coll Cardiol. 2018; 71(8): 832-841, doi: 10.1016/j.jacc.2017.12.032.

43. Briguori C, Sarais C, Pagnotta P, et al. In-stent restenosis in small coronary arteries: impact of strut thickness. J Am Coll Cardiol. 2002; 40(3): 403-409, doi: 10.1016/s0735-1097(02)01989-7, indexed in Pubmed: 12142103.

44. Brugaletta S, Sabate M. Percutaneous treatment of extremely small coronary vessels: does size matter in terms of performance? JACC Cardiovasc Interv. 2017; 10(14): 1389-1391, doi: 10.1016/j.jcin.2017.06.007, indexed in Pubmed: 28728651.

45. Rathore S. Small coronary vessel angioplasty: outcomes and technical considerations. Vasc Health Risk Manag. 2010; 6: 915-922, doi: 10.2147/VHRM.S8161, indexed in Pubmed: 21057576.

46. Mauri L, Orav EJ, Kuntz RE. Late loss in lumen diameter and binary restenosis for drug-eluting stent comparison. Circulation. 2005; 111(25): 3435-3442, doi: 10.1161/CIRCULATIONAHA.104.513952, indexed in Pubmed: 15967844.

47. Ellis SG, Popma JJ, Lasala JM, et al. Relationship between angiographic late loss and target lesion revascularization after coronary stent implantation: analysis from the TAXUS-IV trial. J Am Coll Cardiol. 2005; 45(8): 1193-1200, doi: 10.1016/j. jacc.2004.11.063, indexed in Pubmed: 15837248.

48. Elezi S, Dibra A, Mehilli J, et al. Vessel size and outcome after coronary drug-eluting stent placement. J Am Coll Cardiol. 2006; 48(7): 1304-1309, doi: 10.1016/j.jacc.2006.05.068.

49. Schampaert E, Cohen EA, Schlüter M, et al. C-SIRIUS Investigators. The Canadian study of the sirolimus-eluting stent in the treatment of patients with long de novo lesions in small native coronary arteries (C-SIRIUS). J Am Coll Cardiol. 2004; 43(6): 1110-1115, doi: 10.1016/j.jacc.2004.01.024, indexed in Pubmed: 15028375 .

50. Siontis GCM, Piccolo R, Praz F, et al. Percutaneous coronary interventions for the treatment of stenoses in small coronary arteries: a network meta-analysis. JACC Cardiovasc Interv. 2016; 9(13): 1324-1334, doi: 10.1016/j.jcin.2016.03.025, indexed in Pubmed: 27318845.

51. Kastrati A, Dirschinger J, Boekstegers P, et al. Influence of stent design on 1-year outcome after coronary stent placement: A randomized comparison of five stent types in 1,147 unselected 
patients. Catheter Cardiovasc Interv. 2000; 50(3): 290-297, doi: 10.1002/1522-726x(200007)50:3<290::aid-ccd5>3.0.co;2-w.

52. Kastrati A, Mehilli J, Dirschinger J, et al. Intracoronary stenting and angiographic results. Circulation. 2001; 103(23): 2816-2821, doi: 10.1161/01.cir.103.23.2816.

53. Cassese S, Byrne RA, Tada T, et al. Incidence and predictors of restenosis after coronary stenting in 10004 patients with surveillance angiography. Heart. 2014; 100(2): 153-159, doi: 10.1136/heartjnl-2013-304933, indexed in Pubmed: 24270744.

54. Turco MA, Ormiston JA, Popma JJ, et al. Reduced risk of restenosis in small vessels and reduced risk of myocardial infarction in long lesions with the new thin-strut TAXUS Liberté stent: 1-year results from the TAXUS ATLAS program. JACC Cardiovasc Interv. 2008; 1(6): 699-709, doi: 10.1016/j.jcin.2008.09.007, indexed in Pubmed: 19463387.

55. Lee JZ, Singh N, Ortega G, et al. Composite outcomes in 2.25mm drug eluting stents: a systematic review. Cardiovasc Revasc Med. 2015; 16(4): 237-242, doi: 10.1016/j.carrev.2015.03.008, indexed in Pubmed: 25976630.

56. Tam CC, Chan K, Lam S, et al. One-year clinical outcomes of patients implanted with a Resolute Onyx ${ }^{\mathrm{TM}}$ zotarolimuseluting stent. J Int Med Res. 2018; 46(1): 457-463, doi: 10.1177/0300060517717826, indexed in Pubmed: 28758853.

57. Nestelberger T, Kaiser C, Jeger R. Drug-coated balloons in cardiovascular disease: benefits, challenges, and clinical applications. Expert Opin Drug Deliv. 2020; 17(2): 201-211, doi: 10.1080/17425247.2020.1714590, indexed in Pubmed: 31918593.

58. Mohiaddin H, Wong TD, Burke-Gaffney A, et al. Drug-Coated balloon-only percutaneous coronary intervention for the treatment of de novo coronary artery disease: a systematic review. Cardiol Ther. 2018; 7(2): 127-149, doi: 10.1007/s40119-0180121-2, indexed in Pubmed: 30368735.

59. Kleber FX, Rittger H, Bonaventura K, et al. Drug-coated balloons for treatment of coronary artery disease: updated recommendations from a consensus group. Clin Res Cardiol. 2013; 102(11): 785-797, doi: 10.1007/s00392-013-0609-7, indexed in Pubmed: 23982467.

60. Alfonso F, Scheller B. State of the art: balloon catheter technologies - drug-coated balloon. EuroIntervention. 2017; 13(6): 680-695, doi: 10.4244/EIJ-D-17-00494, indexed in Pubmed: 28844030 .

61. Kufner S, Cassese S, Valeskini M, et al. ISAR-DESIRE 3 Investigators. Long-Term efficacy and safety of paclitaxel-eluting balloon for the treatment of drug-eluting stent restenosis: 3-year results of a randomized controlled trial. JACC Cardiovasc Interv. 2015; 8(7): 877-884, doi: 10.1016/j.jcin.2015.01.031, indexed in Pubmed: 26003022.

62. Richelsen RK, Overvad TF, Jensen SE. Drug-Eluting balloons in the treatment of coronary de novo lesions: a comprehensive review. Cardiol Ther. 2016; 5(2): 133-160, doi: 10.1007/s40119016-0064-4, indexed in Pubmed: 27384194.

63. Latib A, Colombo A, Castriota F, et al. A randomized multicenter study comparing a paclitaxel drug-eluting balloon with a paclitaxel-eluting stent in small coronary vessels. J Am Coll Cardiol. 2012; 60(24): 2473-2480, doi: 10.1016/j.jacc.2012.09.020.

64. Giannini F, Latib A, Ancona MB, et al. A propensity score matched comparative study between paclitaxel-coated balloon and everolimus-eluting stents for the treatment of small coronary vessels. Catheter Cardiovasc Interv. 2017; 90(3): 380-386, doi: 10.1002/ccd.26929, indexed in Pubmed: 28109036.
65. Sinaga DA, Ho HH, Watson TJ, et al. Drug-coated balloons: a safe and effective alternative to drug-eluting stents in small vessel coronary artery disease. J Interv Cardiol. 2016; 29(5): 454-460, doi: 10.1111/joic.12333, indexed in Pubmed: 27578540.

66. Tian J, Tang Yd, Qiao S, et al. RESTORE SVD China Investigators. Two-year follow-up of a randomized multicenter study comparing a drug-coated balloon with a drug-eluting stent in native small coronary vessels: The RESTORE Small Vessel Disease China trial. Catheter Cardiovasc Interv. 2020; 95 Suppl 1: 587-597, doi: 10.1002/ccd.28705, indexed in Pubmed: 31943693.

67. Silverio A, Buccheri S, Venetsanos D, et al. Percutaneous treatment and outcomes of small coronary vessels. JACC: Cardiovascular Interventions. 2020; 13(7): 793-804, doi: 10.1016/j. jcin.2019.10.062.

68. Megaly M, Rofael M, Saad M, et al. Outcomes with drug-coated balloons for treating the side branch of coronary bifurcation lesions. J Invasive Cardiol. 2018; 30(11): 393-399, indexed in Pubmed: 30218555.

69. Masiero G, Mojoli M, Ueshima D, et al. Current concepts on coronary revascularization using BRS in patients with diabetes and small vessels disease. J Thorac Dis. 2017; 9(Suppl 9): S940-S949, doi: 10.21037/jtd.2017.06.36, indexed in Pubmed: 28894600.

70. Mahmoud AN, Barakat AF, Elgendy AY, et al. Long-Term efficacy and safety of everolimus-eluting bioresorbable vascular scaffolds versus everolimus-eluting metallic stents: a meta-analysis of randomized trials. Circ Cardiovasc Interv. 2017; 10(5), doi: 10.1161/CIRCINTERVENTIONS.117.005286, indexed in Pubmed: 28468954.

71. Stiehm M, Wüstenhagen C, Siewert S, et al. Impact of strut dimensions and vessel caliber on thrombosis risk of bioresorbable scaffolds using hemodynamic metrics. Biomed Tech (Berl). 2019; 64(3): 251-262, doi: 10.1515/bmt-2017-0101, indexed in Pubmed: 29933242.

72. Wiebe J, Baquet M, Dörr O, et al. Long-term follow-up and predictors of target lesion failure after implantation of everolimuseluting bioresorbable scaffolds in real-world practice. Int J Cardiol. 2020; 312: 42-47, doi: 10.1016/j.ijcard.2020.02.062, indexed in Pubmed: 32151443.

73. Hideo-Kajita A, Garcia-Garcia H, Kolm P, et al. Comparison of clinical outcomes between Magmaris and Orsiro drug eluting stent at 12 months: Pooled patient level analysis from BIOSOLVE II-III and BIOFLOW II trials. Int J Cardiol. 2020; 300: 60-65, doi: 10.1016/j.ijcard.2019.11.003.

74. Serruys PW, Farooq V, Vranckx P, et al. A global risk approach to identify patients with left main or 3-vessel disease who could safely and efficaciously be treated with percutaneous coronary intervention: the SYNTAX Trial at 3 years. JACC Cardiovasc Interv. 2012; 5(6): 606-617, doi: 10.1016/j.jcin.2012.03.016, indexed in Pubmed: 22721655.

75. O'Connor NJ, Morton JR, Birkmeyer JD, et al. Effect of coronary artery diameter in patients undergoing coronary bypass surgery. Northern New England Cardiovascular Disease Study Group. Circulation. 1996; 93(4): 652-655, doi: 10.1161/01.cir.93.4.652, indexed in Pubmed: 8640991.

76. Rodriguez A, Rodríguez Alemparte M, Fernández Pereira C, et al. LASMAL investigators. Latin American randomized trial of balloon angioplasty vs coronary stenting for small vessels (LASMAL): immediate and long-term results. Am J Med. 2005; 118(7): 743-751, doi: 10.1016/j.amjmed.2005.03.030, indexed in Pubmed: 15989908. 
77. Schofer J, Schlüter M, Gershlick AH, et al. E-SIRIUS Investigators. Sirolimus-eluting stents for treatment of patients with long atherosclerotic lesions in small coronary arteries: doubleblind, randomised controlled trial (E-SIRIUS). Lancet. 2003; 362(9390): 1093-1099, doi: 10.1016/S0140-6736(03)14462-5, indexed in Pubmed: 14550694.

78. Mehilli J, Dibra A, Kastrati A, et al. Intracoronary Drug-Eluting Stenting to Abrogate Restenosis in Small Arteries (ISAR-SMART 3) Study Investigators. Randomized trial of paclitaxel- and sirolimus-eluting stents in small coronary vessels. Eur Heart J. 2006; 27(3): 260-266, doi: 10.1093/eurheartj/ehi721, indexed in Pubmed: 16401670.

79. Cortese B, Micheli A, Picchi A, et al. Paclitaxel-coated balloon versus drug-eluting stent during PCI of small coronary vessels, a prospective randomised clinical trial. The PICCOLETO study. Heart. 2010; 96(16): 1291-1296, doi: 10.1136/hrt.2010.195057, indexed in Pubmed: 20659948.

80. Sim HW, Ananthakrishna R, Chan SP, et al. Treatment of very small de novo coronary artery disease with $2.0 \mathrm{~mm}$ drug-coated balloons showed 1-year clinical outcome comparable with 2.0 mm drug-eluting stents. J Invasive Cardiol. 2018; 30(7): 256-261, indexed in Pubmed: 29656281.

81. Nishiyama N, Komatsu T, Kuroyanagi T, et al. Clinical value of drug-coated balloon angioplasty for de novo lesions in patients with coronary artery disease. Int J Cardiol. 2016; 222: 113-118, doi: 10.1016/j.ijcard.2016.07.156, indexed in Pubmed: 27494722.

82. Funatsu A, Nakamura S, Inoue N, et al. A multicenter randomized comparison of paclitaxel-coated balloon with plain balloon angioplasty in patients with small vessel disease. Clin Res Cardiol. 2017; 106(10): 824-832, doi: 10.1007/s00392-017-1126-x, indexed in Pubmed: 28589231.

83. Her AeY, Ann SH, Singh GB, et al. Comparison of paclitaxelcoated balloon treatment and plain old balloon angioplasty for de novo coronary lesions. Yonsei Med J. 2016; 57(2): 337-341, doi: 10.3349/ymj.2016.57.2.337, indexed in Pubmed: 26847284 .

84. Shin ES, Ann SH, Balbir Singh G, et al. Fractional flow reserveguided paclitaxel-coated balloon treatment for de novo coronary lesions. Catheter Cardiovasc Interv. 2016; 88(2): 193-200, doi: 10.1002/ccd.26257, indexed in Pubmed: 26423017. 